\title{
Are there common genetic and environmental factors behind the endophenotypes associated with the metabolic syndrome?
}

\author{
B. Benyamin • T. I. A. Sørensen • K. Schousboe • \\ M. Fenger $\cdot$ P. M. Visscher $\cdot$ K. O. Kyvik
}

Received: 21 August 2006 / Accepted: 5 June 2007 / Published online: 12 July 2007

(C) Springer-Verlag 2007

\begin{abstract}
Aims/hypothesis The cluster of obesity, insulin resistance, dyslipidaemia and hypertension, called the metabolic syndrome, has been suggested as a risk factor for cardiovascular disease and type 2 diabetes. The aim of the present study was to evaluate whether there are common genetic and environmental factors influencing this cluster in a general population of twin pairs.

Materials and methods A multivariate genetic analysis was performed on nine endophenotypes associated with the metabolic syndrome from 625 adult twin pairs of the GEMINAKAR study of the Danish Twin Registry.
\end{abstract}

Electronic supplementary material The online version of this article (doi:10.1007/s00125-007-0758-1) contains supplementary material, which is available to authorised users.

B. Benyamin · P. M. Visscher

Institute of Evolutionary Biology, University of Edinburgh,

Edinburgh, Scotland, UK

B. Benyamin • P. M. Visscher

Genetic Epidemiology, Queensland Institute of Medical Research,

Brisbane, QLD, Australia

\section{T. I. A. Sørensen}

Danish Epidemiology Science Centre, Institute of Preventive

Medicine, Copenhagen University Hospitals,

Centre for Health and Society,

Copenhagen, Denmark

K. Schousboe $\cdot$ K. O. Kyvik $(\bowtie)$

The Danish Twin Registry, Epidemiology, Institute of Public

Health, University of Southern Denmark,

Sdr. Boulevard 23A,

5000 Odense C, Denmark

e-mail: KKyvik@health.sdu.dk

M. Fenger

Department of Clinical Biochemistry,

University Hospital of Copenhagen,

Hvidovre, Denmark
Results All endophenotypes showed moderate to high heritability (0.31-0.69) and small common environmental variance $(0.05-0.21)$. In general, genetic and phenotypic correlations between the endophenotypes were strong only within sets of physiologically similar endophenotypes, but weak to moderate for other pairs of endophenotypes. However, moderate correlations between insulin resistance indices and either obesity-related endophenotypes or triacylglycerol levels indicated that some common genetic backgrounds are shared between those components.

Conclusions/interpretation We demonstrated that, in a general population, the endophenotypes associated with the metabolic syndrome apparently do not share a substantial common genetic or familial environmental background.

Keywords Correlation · Genetic · Heritability · Insulin resistance $\cdot$ Metabolic syndrome $\cdot$ Multivariate $\cdot$ Obesity

\begin{tabular}{|c|c|}
\hline \multicolumn{2}{|c|}{ Abbreviations } \\
\hline$A$ & additive genetic variance \\
\hline$a^{2}$ & $\begin{array}{l}\text { the proportion of phenotypic variance } \\
\text { explained by additive genetic effects }\end{array}$ \\
\hline AIR & acute insulin response \\
\hline BIGTT & OGTT-derived index \\
\hline$C$ & $\begin{array}{l}\text { common environmental variance shared } \\
\text { by a twin pair }\end{array}$ \\
\hline$c^{2}$ & $\begin{array}{l}\text { the proportion of phenotypic variance } \\
\text { explained by common environmental effects }\end{array}$ \\
\hline$D$ & dominance genetic variance \\
\hline $\mathrm{DZ}$ & dizygote \\
\hline$E$ & $\begin{array}{l}\text { environmental variance specific to } \\
\text { individuals }\end{array}$ \\
\hline$e^{2}$ & $\begin{array}{l}\text { the proportion of phenotypic variance } \\
\text { explained by specific individual } \\
\text { environmental effects }\end{array}$ \\
\hline HOMA & homeostasis model assessment \\
\hline
\end{tabular}




$\begin{array}{ll}\text { HOMA- } & \text { homeostasis model assessment—insulin } \\ \text { IR } & \text { resistance } \\ \text { HOMA- } & \text { homeostasis model assessment—-beta cell } \\ \% \mathrm{~B} & \text { function } \\ \mathrm{S}_{\mathrm{I}} & \text { insulin sensitivity } \\ \mathrm{MZ} & \text { monozygote } \\ \mathrm{QTL} & \text { quantitative trait loci } \\ r G & \text { genetic correlation } \\ r P & \text { phenotypic correlation } \\ \mathrm{TAG} & \text { triacylglycerol }\end{array}$

\section{Introduction}

The metabolic syndrome or insulin resistance syndrome is characterised by clustering of a group of symptoms related to insulin resistance, impaired glucose tolerance or diabetes, obesity, hypertension and dyslipidaemia (raised triacylglycerol [TAG] level and low HDL) [1-3]. The clustering of these symptoms has been suggested to be a better predictor of type 2 diabetes [4] and cardiovascular disease $[5,6]$ than expected from the individual components. Currently, the prevalence of this syndrome is high, not only in developed countries but also in developing countries [7]. In the USA, about $25 \%$ of the adult population have been identified as having the metabolic syndrome [8].

Growing evidence suggests that variation in the individual components of the metabolic syndrome is in part due to genetic effects. A wide range of heritabilities (mostly moderate to high) have been estimated for obesity traits (mean: 0.55; range: 0.37-0.80) [9-14]; insulin-related traits (mean: 0.38; range: 0.08-0.75) [9-11, 13-16]; BP (mean: 0.41; range: $0.16-0.76$ ) [9-13] and lipid traits (mean: 0.46; range: $0.20-0.70$ ) [9-13]. However, the underlying mechanism of the clustering of these characteristics in an individual remains unclear [17].

Correlations between insulin-related endophenotypes and obesity endophenotypes have been previously estimated to be moderate or high $[16,18,19]$, while correlations between other metabolic syndrome endophenotypes have been found to be weak or moderate [12, 16, 19-21]. These correlations have surprisingly often been interpreted as strong evidence for a common factor underlying the metabolic syndrome.

In a joint statement from the American Diabetes Association and the European Association for the Study of Diabetes, Kahn et al. [22] raised several provocative questions, including whether the metabolic syndrome is indeed a syndrome. This question was raised due to the findings that correlations between the metabolic syndrome endophenotypes were weak to moderate. Also, factor analyses have suggested that more than one pathophysio- logical process underlies the syndrome, where more than one-third of total variance in the clustering of the metabolic syndrome components was unexplained by latent factors identified from factor analyses [22].

Twins from the Danish Twin Registry have been used to estimate the heritability of each separate endophenotype associated with the metabolic syndrome in old twins born between 1921 and 1930 (40 for the county of Funen) and recently, based on 625 twin pairs from the study 'The importance of genes, familiar and common environment for the development of insulin resistance, abdominal adiposity and cardiovascular risk factors' (GEMINAKAR) [14, 23]. The aim of the present study was to quantify genetic and environmental (co)variation between these endophenotypes in the GEMINAKAR cohort. Multivariate genetic analysis was employed to provide a complete and objective description of the underlying genetic and environmental architecture of the relationship between traits. In addition to partitioning the phenotypic variance into genetic and environmental components, phenotypic covariance between the traits was partitioned in a similar fashion. To elucidate the underlying genetic and environmental relationships between these endophenotypes in general populations, phenotypic data on 17 endophenotypes associated with the metabolic syndrome were analysed.

\section{Materials and methods}

Participants The data analysed in the present study were part of the GEMINAKAR study [14, 23]. The study is a nationwide Danish project investigating the genetic epidemiology of a wide variety of phenotypes among Danish twins, including endophenotypes of the metabolic syndrome $[14,23]$. The twins were recruited from two cohorts of the nationwide, population-based Danish Twin Registry. Cohort I covers the birth cohorts 1931-1952, while cohort II covers birth cohorts 1953-1982. Invitations to take part in a full day clinical investigation were sent to 2,585 randomly chosen twin pairs who fulfilled the criteria that at least one twin should live within $100 \mathrm{~km}$ from one of the two clinical investigation sites (Odense and Copenhagen) and the pair should not be taking part in other studies at the same time. Cohort II was furthermore chosen based on previous self-report of being healthy. The invitation contained detailed information about the study and its exclusion criteria (i.e. known diabetes or cardiovascular disease, conditions making a progressive maximal bicycle test impossible, pregnancy and breast-feeding). A reply coupon was enclosed for the twins to give information about their present health status and to either consent to or decline telephone contact. If one twin partner in a pair did not respond or was not willing to participate, the pair as 
such was excluded. In 1,098 complete twin pairs $(42.5 \%)$ both were willing and able to participate. A stratified sample of 756 twin pairs underwent an extensive full day clinical examination of a variety of phenotypes. The main focus was on phenotypes related to insulin resistance, obesity and cardiovascular risk factors. The sample included 311 monozygotic (MZ), 314 same-sex dizygotic (DZ) and 131 opposite-sex dizygotic twin pairs with a mean age of 38 years (range 18-67 years). In this study, only samesex twins were analysed (625 twin pairs).

The examinations were run in parallel at The Danish Twin Registry in Odense and at The Institute of Preventive Medicine in Copenhagen from 1997 to 2000. The twins in a pair were examined on the same day. DNA-based microsatellite markers (AmpFISTR Profiler Plus Kit; PE Applied Biosystems, Perkin Elmer, Foster City, CA, USA ) were used to determine zygosity of the twins. The study was approved by all the Danish regional scientific ethical committees, the Danish Data Protection Agency and conducted according to the principles of the Helsinki Declaration.

Phenotypic studies In this study, 13 endophenotypes and four composite phenotypes related to the metabolic syndrome were analysed. The endophenotypes included: BMI; waist circumference; 0 (fasting), 30 and 120 min glucose and insulin (fasting, 30 and $120 \mathrm{~min}$ ) levels; systolic and diastolic BP; HDL and LDL lipoproteins; and TAG. From some of these endophenotypes, four composite phenotypes were derived to obtain two indices for each measure of insulin resistance (OGTT-derived index [BIGTT] of insulin sensitivity $\left.\left[S_{\mathrm{I}}\right]\right|_{0-30-120}[24]$ and homeostasis model assessment [HOMA] of insulin resistance [HOMA-IR] [25]) and beta cell function (BIGTT of acute insulin response $[\mathrm{AIR}]_{0-30-120}[24]$ and HOMA of beta cell function [HOMA-\%B] [25]). The BIGTT indices are new OGTT-derived indices of insulin sensitivity and beta cell function. They have been shown to correlate highly with IVGTT-derived measures and to perform better in predicting insulin resistance and beta cell function than other measures [24].

BMI was calculated as weight $(\mathrm{kg})$ divided by square of height $(\mathrm{m})$, where weight was measured using a standing beam scale to the nearest $0.1 \mathrm{~kg}$ and height was measured using a vertical scale with a horizontal moving headboard to the nearest centimetre. The measure $(\mathrm{cm})$ of midway between the lowest rib and iliac crest was defined as waist circumference [23]. A WHO standard OGTT was carried out after a 10 to $12 \mathrm{~h}$ overnight fast. Blood was taken before oral glucose ingestion and 30 and 120 min later; it was then analysed using the glucose dehydrogenase oxidation method. Then, a two-site, two-step, time-resolved immunofluorometric assay was used to measure serum insulin concentration [14]. Cholesterol, HDL and TAG were measured on fasting blood samples by a colorimetric method (VITROS; Johnson \& Johnson, New Brunswick, NJ, USA). LDL was calculated (Friedewald formula) by subtracting HDL and $(0.45 \times \mathrm{TAG})$ from total cholesterol. Systolic and diastolic BPs were measured after 30 min rest using a conventional mercury sphygmomanometer and hands-free stethoscope. Measurements were taken three times and the mean was used for analysis.

BIGTT- $\left.S_{\mathrm{I}}\right|_{0-30-120}$ was calculated as:

$\exp \left(\begin{array}{l}4.90-\left[0.00402 \times I_{0}\right]-\left[0.000556 \times I_{30}\right] \\ -\left[0.00127 \times I_{120}\right]-\left[0.152 \times G_{0}\right]-\left[0.00871 \times G_{30}\right] \\ -\left[0.0373 \times G_{120}\right]-\left[0.145 \times S_{i}\right]-[0.0376 \times B M I]\end{array}\right)[24]$

BIGTT-AIR ${ }_{0-30-120}$ was calculated as:

$\exp \left(\begin{array}{l}8.20+\left[000178 \times I_{0}\right]+\left[0.00168 \times I_{30}\right] \\ -\left[0.000383 \times I_{120}\right]-\left[0.314 \times G_{0}\right]-\left[0.109 \times G_{30}\right] \\ +\left[0.0781 \times G_{120}\right]+\left[0.0781 \times G_{120}\right]+\left[0.180 \times S_{i}\right] \\ +[0.032 \times \mathrm{BMI}]\end{array}\right)[24]$

$S_{\mathrm{i}}$ is an indicator of sex, with $S_{\mathrm{i}}=0$ for women and $S_{\mathrm{i}}=1$ for men; $G$ stands for glucose and $I$ for insulin with the subscript value indicating the time ( $\mathrm{min}$ ).

HOMA was used to calculate insulin resistance and beta cell function [26].

The phenotypic correlations $(r P)$ between the various indices of insulin resistance are presented in the Electronic supplementary material (ESM) Table 1.

Statistical analyses Descriptive statistics of the data were explored using SPSS version 13.0 for Windows (SPSS, Chicago, IL, USA) to examine trait distributions (Table 1). For endophenotypes showing a non-normal distribution, including BMI, fasting glucose, $120 \mathrm{~min}$ glucose, fasting insulin, 30 min insulin, 120 min insulin, HDL, TAG, HOMAIR, HOMA-\%B and BIGTT-AIR, a $100 \times$ natural logarithm transformation was carried out. For each endophenotype, individuals with a trait value more than $4 \mathrm{SD}$ above or below the mean (after sex and age adjustments) were removed. Outlying families were detected using a standardised Mahalanobis distance (implemented in Mx statistical packages [27]) to compute a $z$ score for each family, taking into account MZ and DZ similarity. Families with a $z$ score of more than 3 SD below or above the mean were removed. A general linear model was fitted to test for the effects of sex and zygosity on the endophenotypes. Twin correlations were calculated after adjustment for age and sex effects.

By comparing the resemblance of MZ twin pairs to that of $\mathrm{DZ}$ twin pairs, a twin design allows the phenotypic variance of phenotypes to be partitioned into underlying additive genetic variance $(A)$, common environmental variance 
Table 1 Metabolic syndrome endophenotypes by sex and zygosity after removal of outliers

\begin{tabular}{|c|c|c|c|c|c|c|}
\hline \multirow[t]{2}{*}{ Endophenotypes } & \multicolumn{2}{|l|}{ Sex } & \multicolumn{2}{|l|}{ Zygosity } & \multirow[t]{2}{*}{ All } & \multirow[t]{2}{*}{ Range } \\
\hline & Men & Women & $\mathrm{MZ}$ & $\mathrm{DZ}$ & & \\
\hline $\begin{array}{l}\text { Number of subjects } \\
\text { (range) }\end{array}$ & $555-582$ & $599-640$ & $572-606$ & $582-616$ & $1,154-1,222$ & \\
\hline Age (years) & $38.01(11.04)$ & $37.70(10.48)$ & $37.81(10.99)$ & $37.89(10.51)$ & $37.85(10.75)$ & $18-67$ \\
\hline BMI $\left(\mathrm{kg} / \mathrm{m}^{2}\right)$ & $24.89(3.00)$ & $23.95(3.76)$ & $24.43(3.31)$ & $24.36(3.59)$ & $24.40(3.45)$ & $16.09-38.58$ \\
\hline Waist circumference $(\mathrm{cm})$ & $89.28(8.75)$ & $78.46(9.49)$ & $83.82(10.52)$ & $83.42(10.72)$ & $83.62(10.62)$ & $58-121$ \\
\hline \multicolumn{7}{|l|}{ Glucose (mmol/1) } \\
\hline Fasting & $4.87(0.49)$ & $4.70(0.46)$ & $4.76(0.50)$ & $4.79(0.47)$ & $4.78(0.48)$ & $3.2-7.6$ \\
\hline $30 \mathrm{~min}$ & $8.65(1.52)$ & $8.27(1.43)$ & $8.41(1.53)$ & $8.49(1.43)$ & $8.45(1.48)$ & $3.6-14.7$ \\
\hline $120 \mathrm{~min}$ & $5.89(1.36)$ & $6.39(1.16)$ & $6.23(1.33)$ & $6.07(1.23)$ & $6.15(1.28)$ & $2.5-13$ \\
\hline \multicolumn{7}{|l|}{ Insulin (pmol/1) } \\
\hline Fasting & $35.88(17.38)$ & $37.95(19.15)$ & $37.48(18.16)$ & $36.43(18.52)$ & $36.95(18.34)$ & $6-150$ \\
\hline $30 \mathrm{~min}$ & $300.57(191.13)$ & $318.19(175.18)$ & $308.28(163.01)$ & $311.12(201.33)$ & $309.71(183.17)$ & $40-1,741$ \\
\hline $120 \mathrm{~min}$ & $138.22(115.13)$ & $188.98(124.62)$ & $170.28(122.29)$ & $158.91(123.06)$ & $164.59(122.75)$ & $8-1,131$ \\
\hline \multicolumn{7}{|l|}{$\mathrm{BP}(\mathrm{mmHg})$} \\
\hline Systolic & $120.24(13.16)$ & $113.38(13.17)$ & $116.50(13.95)$ & $116.81(13.26)$ & $116.65(13.60)$ & $78.0-168.7$ \\
\hline Diastolic & $69.83(10.44)$ & $67.14(10.24)$ & $68.76(10.66)$ & $68.08(10.17)$ & $68.42(10.42)$ & $42.7-112.0$ \\
\hline LDL (mmol/1) & $3.31(1.11)$ & $3.23(1.01)$ & $3.23(1.03)$ & $3.31(1.08)$ & $3.27(1.06)$ & $-0.6-7.4$ \\
\hline HDL (mmol/l) & $1.37(0.40)$ & $1.59(0.44)$ & $1.48(0.43)$ & $1.49(0.44)$ & $1.49(0.43)$ & $0.5-3.6$ \\
\hline TAG $(\mathrm{mmol} / \mathrm{l})$ & $1.33(0.65)$ & $1.17(0.46)$ & $1.26(0.56)$ & $1.23(0.57)$ & $1.25(0.56)$ & $0.2-4.9$ \\
\hline BIGTT-SI & $10.59(3.23)$ & $11.82(3.73)$ & $11.10(3.43)$ & $11.35(3.66)$ & $11.23(3.55)$ & $1.2-24.0$ \\
\hline BIGTT-AIR & $\begin{array}{l}2,369.15 \\
(1,377.43)\end{array}$ & $\begin{array}{l}2,199.79 \\
(1,215.31)\end{array}$ & $\begin{array}{l}2,268.87 \\
(1,064.07)\end{array}$ & $\begin{array}{l}2,293.41 \\
(1,493.49)\end{array}$ & $\begin{array}{l}2,281.24 \\
(1,298.01)\end{array}$ & $650.9-16,732.9$ \\
\hline HOMA-IR & $1.12(0.57)$ & $1.14(0.61)$ & $1.13(0.56)$ & $1.13(0.62)$ & $1.13(0.59)$ & $0.17-5.0$ \\
\hline HOMA-\%B & $84.34(52.38)$ & $103.93(72.05)$ & $98.49(68.25)$ & $90.52(59.43)$ & $94.46(64.04)$ & $9.6-700.5$ \\
\hline
\end{tabular}

Values are mean $(\mathrm{SD})$ and range as indicated.

shared by a twin pair $(C)$, dominance genetic variance $(D)$ and environmental variance specific to individuals $(E)$. The analysis assumes that both types of twins share the same degree of common environmental experiences (the so-called common environment assumption). In a twin design, $D$ and $C$ are confounded, so they cannot be estimated simultaneously. An $A C E$ model was selected in preference to an $A D E$ model, since $\mathrm{MZ}$ twin correlations were less than twice those of DZ correlations (Table 2), which suggested, when assuming no greater $C$ effects than estimated in the $A C E$ model, that there is no dominance genetic effect.

Multivariate genetic analysis to partition the phenotypic (co)variance between endophenotypes into $A, C$ and $E$ components was performed using a maximum likelihood method as implemented in Mx [27]. This analysis estimates the proportion of phenotypic variance of individual endophenotypes due to genetic and environmental variances, as well as the genetic and environmental covariation between endophenotypes. Since BIGTT measurements are functions of other endophenotypes, only nine endophenotypes were included in multivariate genetic analysis, namely BMI, waist circumference, systolic BP, diastolic BP, HDL, LDL, TAG, BIGTT-SI and BIGTT-AIR. For each endophenotype, the standardised residuals after a general linear model correction for the effects of sex and age were used in the
Table 2 Twin intraclass correlations and their 95\% CIs after adjustment for age and sex effects

\begin{tabular}{lll}
\hline Endophenotypes & MZ & Same-sex DZ \\
\hline BMI & $0.71(0.65-0.76)$ & $0.47(0.37-0.55)$ \\
Waist circumference & $0.62(0.55-0.68)$ & $0.39(0.29-0.48)$ \\
Glucose & & \\
Fasting & $0.51(0.41-0.59)$ & $0.35(0.25-0.44)$ \\
30 min & $0.50(0.41-0.58)$ & $0.28(0.17-0.38)$ \\
120 min & $0.44(0.35-0.53)$ & $0.24(0.13-0.34)$ \\
Insulin & & \\
Fasting & $0.44(0.35-0.53)$ & $0.26(0.15-0.36)$ \\
30 min & $0.50(0.41-0.58)$ & $0.32(0.21-0.41)$ \\
120 min & $0.45(0.35-0.53)$ & $0.22(0.11-0.33)$ \\
BP (mmHg) & & \\
Systolic & $0.64(0.57-0.70)$ & $0.41(0.31-0.50)$ \\
Diastolic & $0.66(0.59-0.72)$ & $0.38(0.28-0.47)$ \\
LDL & $0.72(0.66-0.77)$ & $0.39(0.28-0.48)$ \\
HDL & $0.63(0.55-0.69)$ & $0.44(0.34-0.53)$ \\
Triacylglycerol & $0.44(0.34-0.53)$ & $0.33(0.22-0.43)$ \\
BIGTT-SI & $0.48(0.39-0.57)$ & $0.23(0.12-0.34)$ \\
BIGTT-AIR & $0.58(0.50-0.65)$ & $0.37(0.26-0.47)$ \\
HOMA-IR & $0.40(0.30-0.49)$ & $0.25(0.14-0.36)$ \\
HOMA-\%B & $0.50(0.41-0.58)$ & $0.36(0.25-0.45)$ \\
\hline
\end{tabular}


Table 3 The proportion of phenotypic variance of endophenotypes related to the metabolic syndrome due to additive genetic effects $\left(a^{2}\right)$, common environmental effects shared by twin pairs $\left(c^{2}\right)$ and specific individual environmental effects $\left(e^{2}\right)$ from multivariate analyses

\begin{tabular}{llll}
\hline Endophenotypes & \multicolumn{2}{l}{ Variance components } & \\
\cline { 2 - 3 } & $a^{2}(95 \% \mathrm{CI})$ & $c^{2}(95 \% \mathrm{CI})$ & $e^{2}(95 \% \mathrm{CI})$ \\
\hline BMI & $0.59(0.42-0.73)$ & $0.15(0.02-0.26)$ & $0.26(0.22-0.32)$ \\
Waist circumference & $0.45(0.26-0.55)$ & $0.19(0.05-0.32)$ & $0.36(0.31-0.43)$ \\
BP & & & \\
Systolic & $0.45(0.26-0.64)$ & $0.21(0.04-0.38)$ & $0.34(0.29-0.40)$ \\
Diastolic & $0.50(0.31-0.59)$ & $0.16(0.02-0.22)$ & $0.34(0.29-0.41)$ \\
HDL & $0.46(0.28-0.62)$ & $0.20(0.07-0.35)$ & $0.34(0.28-0.41)$ \\
LDL & $0.69(0.54-0.77)$ & $0.06(0.00-0.20)$ & $0.25(0.21-0.30)$ \\
TAG & $0.31(0.10-0.51)$ & $0.19(0.03-0.36)$ & $0.50(0.42-0.59)$ \\
BIGTT-SI & $0.48(0.29-0.59)$ & $0.05(0.00-0.20)$ & $0.47(0.40-0.54)$ \\
BIGTT-AIR & $0.48(0.27-0.66)$ & $0.14(0.00-0.32)$ & $0.38(0.32-0.46)$ \\
\hline
\end{tabular}

Analysis was on the full $A C E$ model.

genetic analysis, because this was computationally much more efficient.

\section{Results}

Descriptive statistics Descriptive statistics of the endophenotypes related to the metabolic syndrome are presented in Table 1. Among nine endophenotypes included in the multivariate genetic analysis, no significant mean differences between zygosity groups were observed for all endophenotypes $(p<0.05)$. Across sexes, mean differences $(p<0.05)$ were observed for most endophenotypes, except for LDL. Therefore, in the multivariate genetic analysis, the endophenotypes were adjusted for the effect of sex.

Based on overlapping 95\% CIs, there was no sex-related difference in MZ and DZ twin correlations for all endophenotypes. Therefore, pooled estimates are shown in Table 2. For all endophenotypes, MZ correlations were consistently larger than those of DZ, suggesting that genetic factors contributed to the phenotypic variation of the metabolic syndrome endophenotypes. Indeed, the results of statistical genetic modelling (described in the next sections) confirmed that a significant part of the phenotypic variation of most endophenotypes was due to genetic factors. Furthermore, the pattern of MZ and DZ correlations, in which $\mathrm{MZ}$ correlations were generally less than twice those of $\mathrm{DZ}$ correlations, indicated that an $A C E$ model was more appropriate to explain the phenotypic variations of the metabolic syndrome endophenotypes than an $A D E$ model.

Genetic analysis Multivariate genetic analysis of nine endophenotypes was performed simultaneously in a single analysis. The proportion of phenotypic variance of the endophenotypes explained by additive genetic $\left(a^{2}\right.$, heritability), common $\left(c^{2}\right)$ and individual specific $\left(e^{2}\right)$ environmental effects from an $A C E$ model are presented in Table 3. Moderate to high heritability were estimated for all endophenotypes (0.31-0.69). All endophenotypes had very small $C$ components $(0.05-0.21)$.

Table 4 Pearson's phenotypic correlations between endophenotypes associated with the metabolic syndrome

\begin{tabular}{|c|c|c|c|c|c|c|c|c|}
\hline Endophenotypes & BMI & Waist circumference & SBP & DBP & HDL & LDL & TAG & BIGTT-SI \\
\hline \multicolumn{9}{|l|}{ BMI } \\
\hline Waist circumference & 0.85 & & & & & & & \\
\hline \multicolumn{9}{|l|}{ BP } \\
\hline Systolic & 0.26 & 0.23 & & & & & & \\
\hline Diastolic & 0.23 & 0.21 & 0.69 & & & & & \\
\hline HDL & -0.14 & -0.17 & -0.02 & 0.02 & & & & \\
\hline LDL & 0.10 & 0.13 & 0.10 & 0.11 & -0.16 & & & \\
\hline TAG & 0.22 & 0.26 & 0.20 & 0.20 & -0.21 & 0.22 & & \\
\hline BIGTT-SI & -0.64 & -0.57 & -0.31 & -0.29 & 0.14 & -0.13 & -0.39 & \\
\hline BIGTT-AIR & 0.45 & 0.39 & 0.12 & 0.12 & -0.12 & 0.08 & 0.11 & -0.43 \\
\hline
\end{tabular}


Table 5 Genetic (upper diagonal) and specific environmental (lower diagonal) correlations from a multivariate (full ACE) model between endophenotypes associated with the metabolic syndrome

\begin{tabular}{lccccccccc}
\hline Endophenotypes & BMI & Waist circumference & SBP & DBP & HDL & LDL & TAG & BIGTT-SI & BIGTT-AIR \\
\hline BMI & & 0.85 & 0.26 & 0.32 & -0.08 & 0.03 & 0.04 & -0.73 \\
Waist circumference & 0.88 & & 0.20 & 0.27 & 0.03 & 0.01 & 0.03 & -0.64 & 0.51 \\
BP & & & & & & & & \\
Systolic & 0.27 & 0.21 & & 0.69 & -0.01 & 0.07 & 0.21 & -0.27 \\
Diastolic & 0.26 & 0.20 & 0.74 & & -0.13 & 0.10 & 0.10 & -0.23 & 0.28 \\
HDL & -0.20 & -0.22 & 0.11 & 0.12 & & -0.08 & -0.53 & 0.16 & 0.01 \\
LDL & 0.24 & 0.23 & 0.08 & 0.07 & -0.20 & & 0.38 & -0.12 \\
TAG & 0.35 & 0.35 & 0.16 & 0.19 & -0.15 & 0.14 & 0.10 & -0.47 \\
BIGTT-SI & -0.67 & -0.59 & -0.26 & -0.24 & 0.12 & -0.13 & -0.34 & 0.01 \\
BIGTT-AIR & 0.44 & 0.37 & 0.11 & 0.15 & -0.15 & 0.05 & 0.23 & -0.42 & -0.53 \\
\hline
\end{tabular}

Phenotypic correlations between endophenotypes were mostly weak to moderate, except for strong correlations between the same groups of endophenotypes: BMI and waist circumference $(r P=0.85)$; systolic $\mathrm{BP}$ and diastolic BP (0.69) (Table 4). Genetic $(r G)$ correlations between endophenotypes estimated from a multivariate analysis (Table 5) were similar to the pattern of phenotypic correlations. Weak to moderate genetic correlations were observed between endophenotypes, except for correlations between: BMI and waist circumference $(r G=0.85)$; systolic $\mathrm{BP}$ and diastolic BP (0.69); HDL and TAG (-0.53). Strong phenotypic and genetic correlations were observed between obesity-related endophenotypes (BMI and waist circumference) and BIGTT indices (Tables 4 and 5). For example, the phenotypic and genetic correlations between BMI and BIGTT-SI were -0.67 and -0.73 , respectively. However, these correlations were confounded by the fact that BMI was part of the equation in the BIGTT indices. Interestingly, moderate negative genetic correlation $(-0.47)$ was observed between BIGTT-SI and triacylglycerol.

None of the common environmental correlations between pairs of endophenotypes was significantly different from zero. The model testing (Table 6) showed that the cross-trait common environmental correlations can be dropped from the model $(p>0.05)$. The environmental correlations between a pair of endophenotypes were mostly due to individual environmental effect.

\section{Discussion}

We have partitioned the observed phenotypic (co)variation of endophenotypes associated with the metabolic syndrome in $\mathrm{MZ}$ and DZ twin pairs into genetic and environmental components. The results showed that genetic factors largely contributed to the individual differences in most endophenotypes. At the same time, the results showed that the endophenotypes related to the metabolic syndrome do not seem to share major common genetic or familial environmental backgrounds, except for the correlations between BIGTT indices and obesity endophenotypes and BIGTT-SI and TAG.

As with any other twin studies, this study should be viewed in the presence of the potential limitations, including whether twins under study are representative of the general population of singleton births. In our study, there is no reason to believe that twins are different from the general population, as we have found the same prevalence of a number of diseases, e.g. type 1 and type 2 diabetes, thyroid diseases, skin diseases and mortality, in Danish twins as in the population (reference list available from K. O. Kyvik). In addition to that, twin studies assume that $\mathrm{MZ}$ and $\mathrm{DZ}$ twins share the same common environmental experiences. This assumption can be tested by comparing phenotypic similarity in twins of perceived versus true zygosity $[28,29]$. The assumption is violated if the phenotypic similarity of the twins is the result of perceived zygosity rather than of true

Table 6 Goodness of fit statistics from multivariate analyses of the endophenotypes related to the metabolic syndrome

\begin{tabular}{lllllll}
\hline Number & Model & Tested against & -211 & $d f$ & $\Delta-211$ & $\Delta d f$ \\
\hline 1 & Full model (ACE) & & $23,525.1$ & 10,537 & & \\
2 & Drop $C$ (off-diagonal) & 1 & $23,556.6$ & 10,573 & 31.5 & 36 \\
$3^{\text {a }}$ & Drop all $C$ (AE model) & 2 & $23,571.6$ & 10,582 & 15 & 0.68 \\
4 & Drop $A$ (off-diagonal) & 1 & $23,615.8$ & 10,573 & 90.7 & 36 \\
\hline
\end{tabular}

$-2 l l-2$ times log-likelihood of data, $\Delta$ difference

${ }^{\mathrm{a}}$ The best fitting model 
zygosity. While this assumption has been tested empirically for some traits [28], this is not commonly practised as part of most twin studies. A well known bias in twin studies is a biased sample of MZ and concordant twins. Our sample of twins originates from a population-based twin registry without oversampling of $\mathrm{MZ}$ pairs; moreover, the sampling for the study was stratified similarly on age, sex and zygosity groups and so there is probably no bias due to oversampling of MZ twin pairs.

It is debatable whether the differences between the older and younger cohort are of importance for the results. The younger cohort was selected as self-reported and healthy on the basis of questionnaire data obtained 3 years before the study, while these data were not available for the older cohort. However, both cohorts were screened for known diabetes and cardiovascular disease before being invited to this clinical investigation. The non-participation among the selected and invited twins may have introduced biases in the distribution of the individual endophenotypes of the metabolic syndrome, but, although unverifiable, we find it unlikely that the intrapair correlations and the mutual relationship between the endophenotypes are biased by this attrition of the study sample compared with the original study population.

Multivariate genetic analysis showed that the heritability estimates for all nine endophenotypes associated with the metabolic syndrome were moderate to high. These results indicate that phenotypic variation in individual endophenotypes is mostly due to genetic effects and this is consistent with the many univariate analyses published by us and others [9-13, 23]. Environmental factors contributing to the variation of the endophenotypes between individuals appear to be mostly experienced by individuals and not shared between family members. We have no evidence that our design and age group are the main reason for small common environmental variance. But since participants were older than 18 years (adults), it is possible that common environmental exposure shared by twin pairs was less marked than when the twin pairs were young.

Previous twin studies have also shown that phenotypic variation in most of the metabolic syndrome-related endophenotypes were largely genetic in origin $[13,16$, 30]. Those studies also reported that common environmental variance shared by family members did not contribute to the variations of the endophenotypes. Some family studies reported smaller genetic components influencing phenotypic variation in the phenotypes related to the metabolic syndrome $[9,12,15,31]$, but the components were still significantly different from zero.

By partitioning the phenotypic covariance between endophenotypes into underlying genetic and environmental components, multivariate genetic analyses have been useful for understanding the relationship between the endopheno- types. The results show that the genetic and phenotypic correlations between the endophenotypes were strong only within physiologically similar endophenotypes, but weak to moderate for other endophenotypes. The strong genetic correlations between endophenotypes within physiologically similar endophenotypes indicate that these endophenotypes, as expected, have many genes in common. These findings may also be due to a direct causal physiological relationship between these endophenotypes, e.g. insulinglucose regulation and its consequences. Multivariate genetic analysis also showed that environmental factors common to a pair of endophenotypes were specific to individuals rather than shared by family members.

While previous studies have suggested common underlying factors influencing the endophenotypes related to the metabolic syndrome [10, 17], genetic, environmental and phenotypic correlations between groups of endophenotypes estimated from the present study did not entirely support this finding. The correlations between endophenotypes were mostly weak, except moderate correlations between insulin-related endophenotypes and either obesity or lipid endophenotypes.

The genetic and environmental correlations estimated from the present study are mostly in line with previous studies [12, 16-21]. Moderate correlations between insulinrelated endophenotypes and obesity traits have previously been reported [16, 18, 19]. For example, using 110 female twin pairs, Samaras et al. [16] reported a genetic correlation of 0.41 between insulin resistance and central fat, while Nelson et al. [18] reported a higher genetic correlation of 0.64 between WHR and fasting insulin. The correlations between BP and other metabolic syndrome endophenotypes have been reported to be weak [17, 19], while Mitchell et al. [31] have reported a near-zero genetic correlation between fasting insulin with either systolic or diastolic BP. The correlations between the other metabolic syndrome endophenotypes have also been reported to be weak or moderate $[12,16,19-21]$. Although the correlations between endophenotypes reported in those studies were similar to those in the present study, these correlations have mostly been interpreted as strong evidence of a common underlying factor influencing the metabolic syndrome.

Knowing that a large proportion of phenotypic variance of individual endophenotypes of the metabolic syndrome traits is explained by genetic factors, the next challenge is to find the genes responsible. Some studies have reported quantitative trait loci (QTL) responsible for the cluster of the metabolic syndrome or its components [32-35]. The $B E A C O N$ gene (also known as UBL5) located on chromosome $19 \mathrm{p}$ has been reported to be associated with the metabolic syndrome-related endophenotypes [36]. Goldin et al. [37] summarised 12 studies reporting QTLs related to the metabolic syndrome components; the QTLs were 
located mostly on chromosomes 1, 3, 5, 6, 7, 10, 14 and 17 . Some studies have tried to locate genes responsible for the metabolic syndrome as a composite variable [38-41]. Given that genetic correlations between the endophenotypes of metabolic syndrome were weak to moderate as suggested from this study, finding genes for the metabolic syndrome as a composite variable may not be a good strategy. This strategy may be appropriate only for physiologically similar endophenotypes, where the genetic correlations are mostly high. Results from our study suggest that it could be a better option to identify separately the genes responsible for each component of the endophenotypes of the metabolic syndrome.

In conclusion, while the individual endophenotypes of the metabolic syndrome were highly heritable, the weak to moderate genetic correlations and no significant common environmental correlations between endophenotypes suggest that the metabolic syndrome comprises a composite set of endophenotypes, which apparently do not share a substantial common genetic and familial environmental background in the general population. However, moderate genetic correlations between BIGTT-SI and either obesity endophenotypes or TAG indicate that some common genetic backgrounds are shared between those components.

Acknowledgements The GEMINAKAR project was supported by grants from the Danish Medical Research Council, the Danish Diabetes Association, the NOVO Foundation, the Danish Heart Foundation, Apotekerfonden, the Foundation of A. and J. Louis-Hansen, the Foundation of Direktor E. Danielsen and wife, the Foundation of Direktor K. Bonnelycke and wife Grethe, the Foundation of Laegevidenskabens Fremme, the Foundation of A. F. Bolding, the Foundation of O. William and E. B. Olesen, the Faculty of Health at University of Southern Denmark, the Danish National Science Foundation, T. Steenbeck's Foundation, the Gangsted Foundation and King Christian the Tenth's Foundation. We would like to thank A. McRae for helpful comments on the earlier draft of the manuscript and J. Hansen for helping with statistical analysis. B. Benyamin was funded by a School of Biological Sciences Studentship of the University of Edinburgh and by an Overseas Research Students Award. P. M. Visscher was funded by the UK Biotechnology and Biological Sciences Research Council. K. O. Kyvik received funding from the European Union Contract No. QLG2-CT-2002-01254 (the GenomEUtwin project). The Danish Epidemiology Science Centre is supported by the National Danish Science Foundation. Finally, we would like to thank all twins participating in the GEMINAKAR Study.

Duality of interest The authors declare that there is no duality of interest associated with this manuscript.

\section{References}

1. Eckel RH, Grundy SM, Zimmet PZ (2005) The metabolic syndrome. Lancet 365:1415-1428

2. Roche HM, Phillips C, Gibney MJ (2005) The metabolic syndrome: the crossroads of diet and genetics. Proc Nutr Soc 64:371-377
3. Shaw DI, Hall WL, Williams CM (2005) Metabolic syndrome: what is it and what are the implications? Proc Nutr Soc 64:349-357

4. Laaksonen DE, Lakka HM, Niskanen LK, Kaplan GA, Salonen JT, Lakka TA (2002) Metabolic syndrome and development of diabetes mellitus: application and validation of recently suggested definitions of the metabolic syndrome in a prospective cohort study. Am J Epidemiol 156:1070-1077

5. Girman CJ, Dekker JM, Rhodes T et al (2005) An exploratory analysis of criteria for the metabolic syndrome and its prediction of long-term cardiovascular outcomes: the Hoorn Study. Am J Epidemiol 162:438-447

6. Sundstrom J, Riserus U, Byberg L, Zethelius B, Lithell H, Lind L (2006) Clinical value of the metabolic syndrome for long term prediction of total and cardiovascular mortality: prospective, population based cohort study. BMJ 332:878-882

7. Cameron AJ, Shaw JE, Zimmet PZ (2004) The metabolic syndrome: prevalence in worldwide populations. Endocrinol Metab Clin North Am 33:351-375

8. Ford ES, Giles WH (2003) A comparison of the prevalence of the metabolic syndrome using two proposed definitions. Diabetes Care 26:575-581

9. Freeman MS, Mansfield MW, Barrett JH, Grant PJ (2002) Heritability of features of insulin resistance syndrome in a community-based study of healthy families. Diabet Med 19:994-999

10. Li JKY, Ng MCY, So WY et al (2006) Phenotypic and genetic clustering of the metabolic syndrome in Chinese families with type 2 diabetes mellitus. Diabetes Metab Res Rev 22:46-52

11. Lin H-F, Boden-Albala B, Juo SH, Park N, Rundek T, Sacco RL (2005) Heritabilities of the metabolic syndrome and its components in the Northern Manhattan Family Study. Diabetologia 48:2006-2012

12. Martin LJ, North KE, Dyer T, Blangero J, Comuzzie AG, Williams J (2003) Phenotypic, genetic, and genome-wide structure in the metabolic syndrome. BMC Genet 4(Suppl.1):S95

13. Poulsen P, Vaag A, Kyvik K, Beck-Nielsen H (2001) Genetic versus environmental aetiology of the metabolic syndrome among male and female twins. Diabetologia 44:537-543

14. Schousboe K, Visscher PM, Henriksen JE, Hopper JL, Sørensen TI, Kyvik KO (2003) Twin study of genetic and environmental influences on glucose tolerance and indices of insulin sensitivity and secretion. Diabetologia 46:1276-1283

15. Henkin L, Bergman RN, Bowden DW et al (2003) Genetic epidemiology of insulin resistance and visceral adiposity: the IRAS Family Study design and methods. Ann Epidemiol 13: 211-217

16. Samaras K, Nguyen TV, Jenkins AB et al (1999) Clustering of insulin resistance, total and central abdominal fat: same genes or same environment? Twin Res 2:218-225

17. Hong Y, Pedersen NL, Brismar K, Faire UD (1997) Genetic and environmental architecture of the features of the insulin-resistance syndrome. Am J Hum Genet 60:143-152

18. Nelson TL, Vogler GP, Pedersen NL, Hong Y, Miles TP (2000) Genetic and environmental influences on body fat distribution, fasting insulin levels and CVD: are the influences shared? Twin Res 3:43-50

19. Tregouet DA, Herbeth B, Juhan-Vague I, Siest G, Ducimetiere P, Tiret L (1999) Bivariate familial correlation analysis of quantitative traits by use of estimating equation: application to a familial analysis of the insulin resistance syndrome. Genet Epidemiol 16:69-83

20. Perusse L, Rice T, Despres JP, Rao DC, Bouchard C (1997) Cross-trait familial resemblance for body fat and blood lipids: familial correlations in the Quebec Family Study. Arterioscler Thromb Vasc Biol 17:3270-3277 
21. Rainwater DL, Mitchell BD, Mahaney MC, Haffner SM (1997) Genetic relationship between measures of HDL phenotypes and insulin concentrations. Arterioscler Thromb Vasc Biol 17:34143419

22. Kahn R, Buse J, Ferrannini E, Stern M (2005) The metabolic syndrome: time for a critical appraisal. Joint statement from the American Association and the European Association for the Study of Diabetes. Diabetes Care 28:2289-2304

23. Schousboe K, Visscher PM, Erbas B et al (2004) Twin study of genetic and environmental influences on adult body size, shape and composition. Int $\mathrm{J}$ Obes 28:39-48

24. Hansen T, Drivsholm T, Urhammer SA et al (2007) The BIGTT test: a novel test for simultaneous measurement of pancreatic betacell function, insulin sensitivity, and glucose tolerance. Diabetes Care 30:257-262

25. Matthews DR, Hosker JP, Rudenski AS, Naylor BA, Treacher DF, Turner RC (1985) Homeostasis model assessment: insulin resistance and beta-cell function from fasting plasma glucose and insulin concentrations in man. Diabetologia 28:412-419

26. Diabetes Trials Unit, HOMA calculator. Available at http://www. dtu.ox.ac.uk, accessed 16 June 2007

27. Neale MC, Boker SM, Xie G, Maes HH (2002) Mx: statistical modelling. Department of Psychiatry, Virginia Commonwealth University, Richmond. Available at http://www.vcu.edu/mx/ documentation.html, accessed 16 June 2007

28. Kendler KS, Neale MC, Kessler RC, Heath AC, Eaves LJ (1993) A test of the equal-environment assumption in twin studies of psychiatric illness. Behav Genet 23:21-27

29. Scarr $S$ (1968) Environmental bias in twin studies. Eugen Q 15:34-40

30. Edwards KL, Newman B, Mayer E, Selby JV, Krauss RM, Austin MA (1997) Heritability of factors of the insulin resistance syndrome in women twins. Genet Epidemiol 14:241-253

31. Mitchell BD, Kammerer CM, Mahaney MC et al (1996) Pleiotropic effects of genes influencing insulin levels on lipoprotein and obesity measures. Arterioscler Thromb Vasc Biol 16:281-288
32. An P, Freedman BI, Hanis CL et al (2005) Genome-wide linkage scans for fasting glucose, insulin, and insulin resistance in the National Heart, Lung, and Blood Institute Family Blood Pressure Program. Diabetes 54:909-914

33. Kissebah AH, Sonnenberg GE, Myklebust J et al (2000) Quantitative trait loci on chromosome 3 and 17 influence phenotypes of the metabolic syndrome. PNAS 97:14478-14483

34. Rich SS, Bowden DW, Haffner SM et al (2005) A genome scan for fasting insulin and fasting glucose identifies a quantitative trait locus on chromosome 17p: the Insulin Resistance Atherosclerosis Study (IRAS) Family Study. Diabetes 54:290-295

35. Shearman AM, Ordovas JM, Cupples LA et al (2000) Evidence for a gene influencing the TG/HDL-C ratio on chromosome 7q32.3-qter: a genome-wide scan in the Framingham Study. Hum Mol Genet 9:1315-1320

36. Jowett JB, Elliot KS, Curran JE et al (2004) Genetic variation in BEACON influences quantitative variation in metabolic syndromerelated phenotypes. Diabetes 53:2467-2472

37. Goldin LR, Camp NJ, Keen KJ et al (2003) Analysis of metabolic syndrome phenotypes in Framingham Heart Study families from genetic analysis workshop 13. Genet Epidemiol 25:S78-S89

38. Loos RJF, Katzmarzyk PT, Rao DC et al (2003) Genome-wide linkage scan for the metabolic syndrome in the HERITAGE Family Study. J Clin Endocrinol Metab 88:5935-5943

39. McQueen MB, Bertram L, Rimm EB, Blacker D, Santangelo SL (2003) A QTL genome scan of the metabolic syndrome and its component traits. BMC Genet 4(Suppl.1):S96

40. Ng MCY, So WY, Lam VKL et al (2004) Genome-wide scan for metabolic syndrome and related quantitative traits in Hong Kong Chinese and confirmation of a susceptibility locus in chromosome 1q21-q25. Diabetes 53:2676-2683

41. Tang W, Miller MB, Rich SS et al (2003) Linkage analysis of a composite factor for the multiple metabolic syndrome. Diabetes $52: 2840-2847$ 